\title{
Peran Komunikasi Penyuluh Lapangan dalam Pembangunan Agribisnis Ternak Itik di Kabupaten Brebes
}

\section{The Role of Livestock Extension Communications for the Development of Ducks Agribusiness in Brebes Regency}

\author{
S. N. Utami* dan S. K. Sita \\ Program Studi Agribisnis Universitas Muhadi Setiabudi \\ Jl. P. Diponegoro KM 2 Wanasari Brebes 52252 \\ *E-mail: sucinu@umus.ac.id \\ (Diterima: 18 April 2018; Disetujui: 27 Juni 2018)
}

\begin{abstract}
ABSTRAK
Penelitian ini bertujuan untuk mengoptimalkan peran penyuluh lapangan dalam rangka pengembangan agribisnis ternak itik di Kabupaten Brebes. Penelitian ini dilakukan dengan menggunakan pendekatan subjektif dengan data kualitatif. Metode dalam pengambilan data adalah dengan indepth interview, survei, dan studi pustaka yang diharapkan dapat menunjang kegiatan penelitian. Wawancara dilakukan terhadap penyuluh lapangan serta peternak lokal di tiga wilayah kecamatan yang dipilih secara random sampling. Analisis data menggunakan metode deskriptif untuk mengetahui keefektifan komunikasi oleh penyuluh lapangan yang ada di wilayah Kabupaten Brebes. Dari hasil wawancara dan survei lapangan, kemudian dirumuskan model komunikasi yang efektif dengan menggunakan analisis SWOT. Analisis SWOT tersebut dijadikan dasar untuk pengambilan keputusan dalam rangka pengembangan agribisnis ternak itik di Kabupaten Brebes. Kesimpulan yang didapat bahwa model komunikasi yang sesuai adalah dengan metode yang dibutuhkan oleh petani. Penyuluh memiliki peranan yang sangat penting dalam pengembangan pembangunan agribisnis ternak itik di Kabupaten Brebes. Hal tersebut didukung dengan komunikasi personal yang baik antara penyuluh lapangan dengan peternak itik di Kabupaten Brebes.
\end{abstract}

Kata kunci: komunikasi, penyuluh lapangan, pengembangan agribisnis ternak itik

\section{ABSTRACT}

This research aims to optimize the role of the farm extension has a important role for the duck agribusiness development. This research was conducted using a subjective approach to qualitative data. Data were collected using in-depth interviews, direct surveys, and literature were expected to support research activities. Interviews were conducted with farm extension as well as the local farmers in three sub-districts were selected by random sampling. Data analysis using descriptive methods to determine the effectiveness of communication by government farm staff in Brebes. From interviews and field surveys, then formulated a model of effective communication by using SWOT analysis. The SWOT analysis as a basis for decision making for the development of duck agribusiness in Brebes. It was concluded that the success of education was determined by the model of communication made by farm extension and adapted to the needs of farmers, namely the accuracy of the materials, methods, and media used. Farm extension has a very important role in the development of duck agribusiness in Brebes. This was supported by good personal communication between farm extension with duck farmers in Brebes.

Keywords : communication, farm extension, development of duck agribusiness 


\section{PENDAHULUAN}

Ternak itik merupakan komoditas agribisnis di bidang peternakan yang sudah dikenal luas oleh masyarakat di Kabupaten Brebes. Ternak itik merupakan produk andalan peternakan di Kabupaten Brebes selain komoditas pertanian bawang merah. Umumnya itik dibudidayakan dengan cara tradisional yang tentunya berdampak terhadap minimnya pendapatan. Pendapatan rendah akan mempengaruhi produktivitas peternak.

Produktivitas peternak dapat ditingkatkan dengan cara mengoptimalkan pengetahuan peternak. Tingkat pengetahuan peternak dapat ditingkatkan dengan metode komunikasi. Disini peran penyuluh lapangan sangat diperlukan dalam upaya transfer teknologi kepada peternak mengenai manajemen ternak itik yang tepat (Abdullah, 2008).

Menurut Indardi (2016), penyuluh lapangan dihadapkan dengan permasalahan masih rendahnya tingkat adopsi inovasi peternak terhadap informasi-informasi yang bermanfaat bagi pengembangan agribisnis ternak itik mereka. Oleh karena itu peternak harus diberi informasi (melalui penyuluhan) oleh penyuluh lapangan tentang pengetahuan dan teknologi baru di bidang agribisnis ternak itik sehingga peternak dapat menerapkan teknologi tersebut untuk meningkatkan produktivitas ternak mereka.

Penyuluhan peternakan diharapkan bisa meningkatkan partisipasi masyarakat dalam pengembangan pembangunan perternakan itik di wilayah Kabupaten Brebes. Suparta (2007) menduga bahwa komunikasi telah mengalami perpindahan dari pola Top Down ke pola Dyadic. Pola komunikasi yang berkembang sekarang harus merupakan partisipasi dan transfer pengetahuan serta pengalaman dalam hal ini peternak berperan sebagai partner sehingga terjadi sinergi antara teknologi terkini dengan tradisi lokal setempat.

Undang-undang Republik Indonesia Nomor 16 Tahun 2006 menyebutkan bahwa penyuluhan adalah proses dimana pelaku utama dan pelaku usaha bersedia belajar mengenai akses informasi pasar untuk peningkatan produktivitas usaha dalam pelestarian fungsi lingkungan. Sistem penyuluhan adalah rangkaian pengetahuan pelaku utama dan pelaku usaha dalam kegiatan penyuluhan.

Penyuluhan berfungsi untuk mendorong partisipasi peternak dalam keberanian mengambil keputusan yang tepat bagi usahanya (Ramirez dan Wendy, 2004). Melalui kegiatan penyuluhan yang efektif, peternak mempunyai kesempatan yang sama dalam upaya meningkatkan taraf hidupnya.

Penelitian ini bertujuan untuk merumuskan strategi pengembangan agribisnis ternak itik di Kabupaten Brebes melalui pengoptimalan peran penyuluh lapangan yang ada di Kabupaten Brebes. Data diambil dengan studi literatur pengembangan ternak itik. Diharapkan dengan adanya studi literatur ini, dapat menghasilkan strategi komunikasi yang tepat untuk diterapkan bagi masyarakat peternak maupun pemerintah daerah Kabupaten Brebes dalam rangka pengembangan agribisnis ternak itik di Kabupaten Brebes.

\section{METODE}

Penelitian ini dilakukan dengan menggunakan pendekatan subjektif dengan data kualitatif. Pengambilan data dilakukan dengan menggunakan metode wawancara secara mendalam (indepth interview), survei langsung, dan studi pustaka yang diharapkan dapat menunjang kegiatan penelitian. Wawancara dilakukan terhadap penyuluh lapangan serta peternak lokal di wilayah sampling.

Penelitian ini menggunakan data primer maupun data sekunder. Data primer diambil dari responden maupun berdasarkan observasi, Data sekunder bersumber dari informasi pihak luar. Analisis data dengan analisis deskriptif untuk mengetahui komunikasi oleh penyuluh 
lapangan yang ada di wilayah Kabupaten Brebes serta menggambarkan keefektifan penyuluh lapangan dalam mentransfer teknologi untuk peternak.

Dari hasil wawancara dan survei lapangan, kemudian dirumuskan model komunikasi yang efektif dengan menggunakan analisis SWOT. Analisis SWOT tersebut dijadikan dasar untuk pengambilan keputusan dalam rangka pengembangan agribisnis ternak itik di Kabupaten Brebes.

\section{HASIL DAN PEMBAHASAN}

\section{Karakteristik Peternak}

Sebagian besar peternak itik di Kabupaten Brebes mengusahakan ternak itik hanya sebagai usaha sampingan di selasela mata pencaharian utama sebagai petani. Usaha ternak itik biasanya dimanfaatkan sebagai tabungan masa depan. Sebagian besar pendidikan responden adalah tingkat Sekolah Dasar.

\section{Peran Komunikasi/ Penyuluhan}

dalam penyuluhan sangat efektif digunakan pembangunan. Penyuluhan difokuskan untuk peternak itik di Kabupaten Brebes. Output yang dihasilkan bertujuan untuk meningkatkan motivasi peternak dalam meningkatkan pendapatan dengan cara merubah paradigma beternak dari cara tradisional ke dalam metode beternak yang modern. Penyuluhan yang efektif akan didapatkan dari kreasi peternak sendiri. Disini peran penyuluh hanya sebagai fasilitator dan sebagai mediator bagi peternak dalam menyelesaikan masalah-masalah teknis dalam kegiatan ternak masyarakat.

Program penyuluhan dari penyuluh lapangan harus mengintegrasi beberapa bidang seperti pendidikan dan kesehatan untuk mendukung pemberdayaan masyarakat. Penelitian di lapangan juga menunjukkan metode penyuluh lapangan dalam memotivasi peternak dengan diadakannya suatu forum diskusi antar peternak dengan petugas yang terkait. Penyuluh lapangan melakukan pendekatan individu dengan peternak lewat kunjungan langsung ke rumah peternak. Pendekatan secara individu tersebut dilakukan dengan maksud supaya peternak dapat menerapkan secara langsung apa yang disampaikan oleh penyuluh lapangan.

\section{Permasalahan Umum}

Permasalahan yang kerap terjadi antara komunikasi penyuluh lapangan dengan peternak adalah hubungan antara keduanya yang kurang dibina secara baik. Seringkali peternak menganggap penyuluh lapangan hanya sebagai petugas pemerintah yang akan menghambat pekerjaan mereka. Penyuluh lapangan seringkali melaksanakan tugas sebatas administrasi struktural saja dengan mengesampingkan tugas fungsional sebagai penyuluh lapangan yang harus aktif terjun ke masyarakat. Hal ini menjadikan program pengembangan agribisnis khususnya di bidang peternakan menjadi terhambat.

Hal ini bisa diatasi dengan menjadikan penyuluh lapangan sebagai mitra kerja yang baik bagi masyarakat. Penyuluh lapangan perlu melakukan pendekatan individual kepada peternak untuk mengetahui secara langsung permasalahan-permasalahan yang terjadi di masyarakat.

\section{Analisis Swot}

Sesuai dengan tujuan penelitian, hasil penelitian didapat dengan menggunakan pendekatan analisis SWOT. Tahap awal dalam melakukan analisis SWOT adalah dilakukan analisis terhadap matriks IFAS dan EFAS.

\section{Matriks IFAS dan EFAS}

Tahapan-tahapan dalam melakukan analisis Internal Factor Analysis Summary (IFAS) dan External Factor Analysis Summary (EFAS) adalah:

1. Penentuan faktor kekuatan, kelemahan, peluang, dan ancaman.

2. Penentuan rating masing-masing faktor dari 4 -1.

3. Pemberian bobot masing-masing faktor dari $1-0$. 
Tabel 1. Analisis SWOT Peran Komunikasi Oleh Penyuluh Lapangan dalam Pengembangan Pembangunan Agribisnis Ternak Itik di Kabupaten Brebes.

\begin{tabular}{|c|c|c|}
\hline Faktor Internal & $\begin{array}{l}\text { Kekuatan (S) } \\
\text { 1. Besarnya populasi ternak itik di } \\
\text { Kabupaten Brebes } \\
\text { 2. Tersedia penyuluh lapangan } \\
\text { dalam jumlah yang cukup } \\
\text { 3. Banyaknya media informasi } \\
\text { tentang peternakan } \\
\text { 4. Brebes merupakan wilayah sentra } \\
\text { peternakan itik }\end{array}$ & 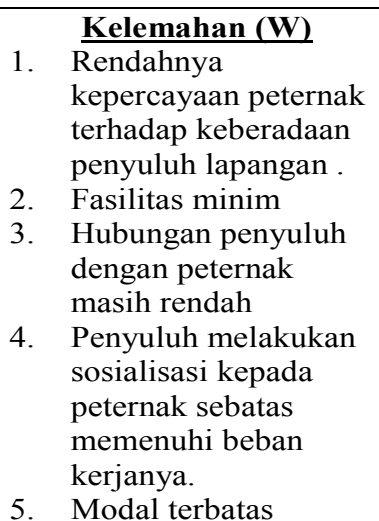 \\
\hline 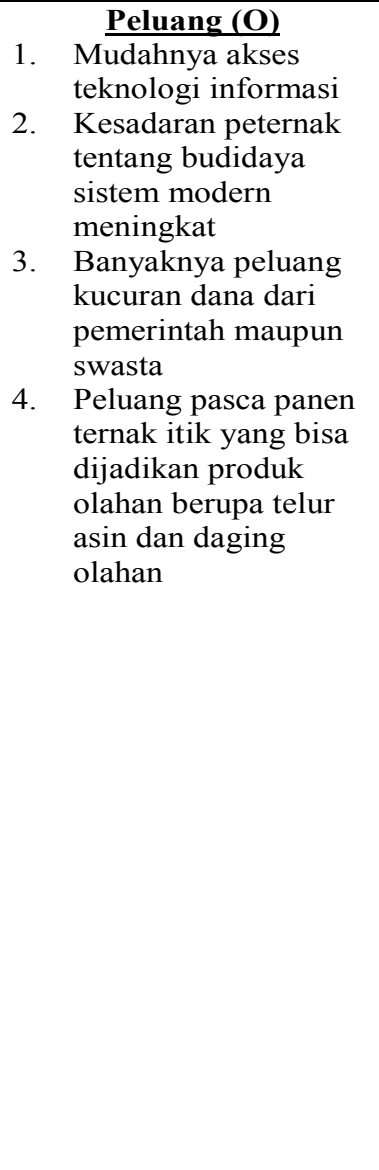 & 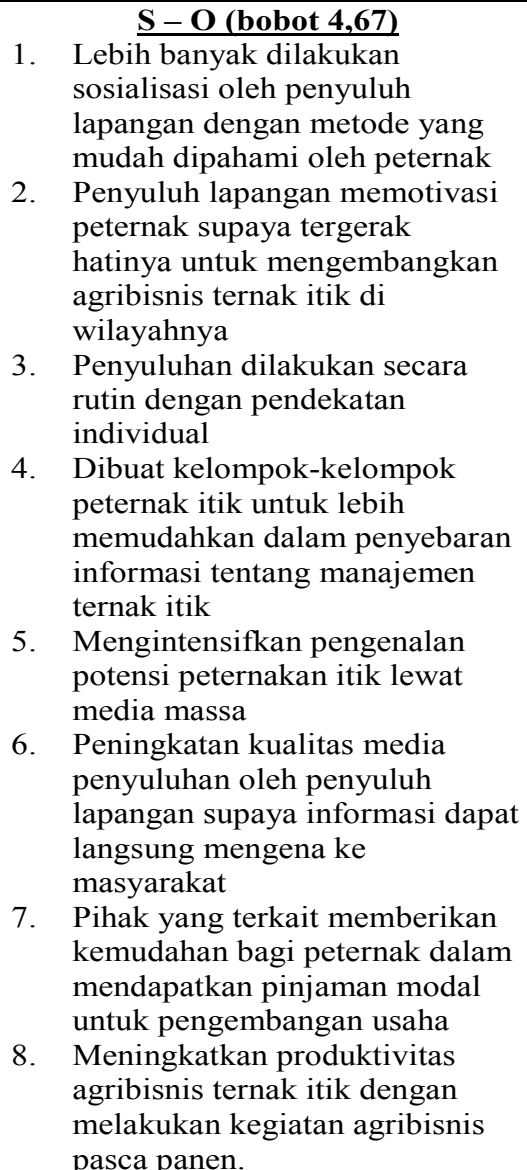 & 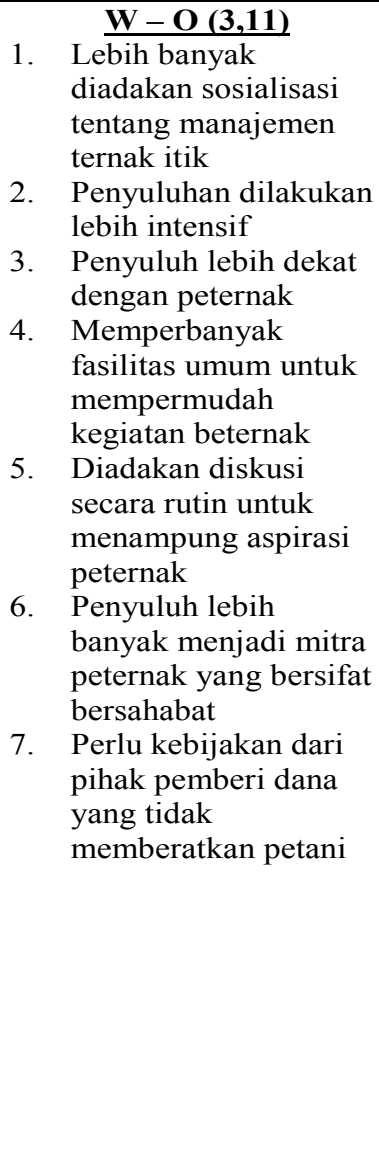 \\
\hline $\begin{array}{ll}\text { 1. } & \begin{array}{l}\text { Ancaman }(\mathbf{T}) \\
\text { semaya beternak } \\
\text { semin memudar }\end{array} \\
\text { 2. } & \begin{array}{l}\text { Hubungan peternak } \\
\text { dengan pemerintah }\end{array} \\
\text { kurang harmonis } \\
\text { 3. } & \begin{array}{l}\text { Kurangnya fasilitas } \\
\text { bagi penyuluh }\end{array}\end{array}$ & 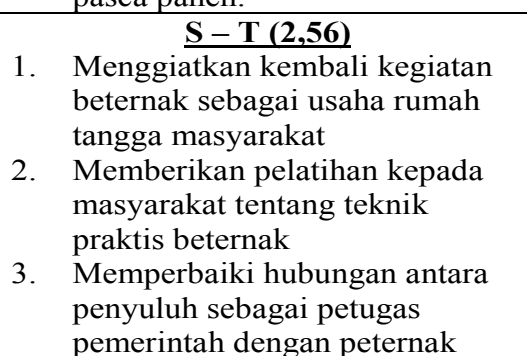 & \begin{tabular}{ll} 
1. & \multicolumn{1}{|}{$\mathbf{W}-\mathbf{T}(\mathbf{1 , 4 5})$} \\
Peningkatan kualitas \\
SDM
\end{tabular} \\
\hline
\end{tabular}


Hasil analisis faktor internal bahwa faktor kekuatan utama dengan nilai terbesar adalah faktor banyaknya populasi ternak maupun peternak itik di Kabupaten Brebes. Hal tersebut didasari Kabupaten Brebes yang merupakan sentra produksi telur asin yang merupakan produk olahan ternak berbahan dasar telur itik. Sedangkan kelemahan utama adalah rendahnya kepercayaan peternak terhadap keberadaan penyuluh lapangan.

Faktor strategis eksternal yang paling mempengaruhi peran penyuluh dalam pengembangan agribisnis ternak itik di Kabupaten Brebes adalah mudahnya akses teknologi informasi yang dengan mudah didapat melalui media internet. Peluang ini memungkinkan penyuluh lapangan mencari metode-metode yang efektif dalam menyebarluaskan informasi manajemen ternak itik kepada peternak. Sebaliknya ancaman utama yang dihadapi oleh peternak adalah budaya beternak di masyarakat yang semakin memudar. Masyarakat cenderung lebih memilih untuk meninggalkan kampung halaman untuk mengadu nasib ke luar daerah. Kondisi tersebut dimungkinkan akan mempengaruhi pengembangan agribisnis ternak itik di Kabupaten Brebes. Semakin sedikit masyarakat yang termotivasi untuk beternak itik.

Berdasarkan identifikasi matriks IFAS dan EFAS di atas, dapat disusun suatu strategi penguatan komunikasi oleh penyuluh lapangan dalam rangka pengembangan pembangunan agribisnis ternak itik di Kabupaten Brebes. Strategi tersebut dapat diidentifikasi melalui matriks SWOT (Tabel 1).

Dari Focus Group Discussion (FGD), diketahui permasalahan yang dihadapi oleh peternak dalam pengembangan agribisnis ternak itik antara lain ada pada rendahnya kualitas SDM, modal yang terbatas, serta kurang eratnya hubungan antara peternak dengan penyuluh. Dari kenyataan tersebut, berbagai alternatif strategi dapat dirumuskan dengan menggunakan matriks SWOT. Keunggulan dari penggunaan matriks SWOT adalah kemudahan dalam menyusun formulasi strategi dngan hanya melihat faktor strategi internal dan eksternal.

Sesuai dengan Rangkuti (2006) apabila matriks internal internal menunjuk pada kuadran 1 berarti agribisnis ternak itik di Kabupaten Brebes berada pada kondisi strategi agresif. Alternatif strategi yang perlu dilakukan adalah dengan melihat formulasi strategi yang ada di kuadran 1 dengan bobot tertinggi $(4,67)$ yaitu:

1. Lebih banyak dilakukan sosialisasi oleh penyuluh lapangan dengan metode yang mudah dipahami oleh peternak

2. Penyuluh lapangan memotivasi peternak supaya tergerak hatinya untuk mengembangkan agribisnis ternak itik di wilayahnya

3. Penyuluhan dilakukan secara rutin dengan pendekatan individual

4. Pembentukan kelompok-kelompok peternak itik untuk lebih memudahkan dalam penyebaran informasi tentang manajemen ternak itik

5. Mengintensifkan pengenalan potensi peternakan itik lewat media massa

6. Peningkatan kualitas media penyuluhan oleh penyuluh lapangan supaya informasi dapat langsung mengena ke masyarakat

7. Pihak yang terkait memberikan kemudahan bagi peternak dalam mendapatkan pinjaman modal untuk pengembangan usaha

8. Meningkatkan produktivitas agribisnis ternak itik dengan melakukan kegiatan agribisnis pasca panen.

\section{KESIMPULAN}

Penelitian menunjukkan bahwa penyuluhan dikategorikan berhasil apabila informasi yang disampaikan sesuai dengan apa yang dibutuhkan oleh peternak. Penyuluh memiliki peranan yang sangat penting dalam pengembangan pembangunan agribisnis ternak itik di Kabupaten Brebes. Hal tersebut didukung dengan komunikasi personal 
yang baik antara penyuluh lapangan dengan peternak itik di Kabupaten Brebes. Penyuluh lapangan perlu mengembangkan metode komunikasi yang persuasif sehingga secara tidak langsung dapat memotivasi peternak dalam meningkatkan usahanya.

Di samping itu perlu partisipasi aktif dari peternak dalam mengadopsi informasi dari penyuluh untuk meningkatkan efisiensi dan produktivitas dalam beternak. Peternak harus memandang penyuluh lapangan sebagai mitra kerja bukan sebagai seorang petugas dari pemerintah yang menjalankan kewajiban hanya sebagai kegiatan administrasi biasa.

\section{SARAN}

Rekomendasi untuk mendukung penelitian ini adalah diperlukan pembinaan secara intensif bagi penyuluh lapangan tentang tugas dan fungsinya sebagai mitra peternak yang berkewajiban menyampaikan informasi dengan jelas kepada masyarakat. Kemudian membentuk dan memperkuat kelembagaan kelompok ternak untuk mengakomodasi permasalahan-permasalahan yang dihadapi oleh peternak. Pemerintah daerah setempat perlu menyusun kebijakan-kebijakan yang dapat mengembalikan peran komunikasi oleh penyuluh lapangan sebagai salah satu penggerak pengembangan pengembangan agribisnis ternak itik di Kabupaten Brebes.

\section{DAFTAR PUSTAKA}

Abdullah, A. 2008. Peranan Penyuluhan dan Kelompok Tani Ternak untuk Meningkatkan Adopsi Teknologi dalam Peternakan Sapi Potong. Dalam Prosiding Seminar Nasional Sapi Potong - Palu, 24 November 2008: 188 $-195$.

Anggriyani, E. 2014. Analisis Peran Komunikasi Antara Kelompok dalam Jaringan Komunikasi. Sains Peternakan Vol 12 (2) September 2014: 107 - 113. Handayani, M, A. Setiadi, S. Gayatri, dan
H. Setiyawan. 2007. Profil Usaha Peternakan Itik di Kabupaten Brebes. Journal of Animal Agricultural Socioeconomics 3 (1), Januari 2007: 20 - 25.

Indardi. 2016. Pengembangan Model Komunikasi dalam Pemberdayaan Masyarakat Tani. AGRARIS: Journal of Agribusiness and Rural Development Research 2 (1): $75-84$.

Mulyana, D. 2001. Metodologi Penelitian Kualitatif, Paradigma Baru Ilmu Komunikasi dan Ilmu Sosial Lainnya. Bandung. Remaja Rosdakarya.

Pusat Pengembangan Penyuluhan Pertanian. 2008. Pedoman Revitalisasi Penyuluhan Pertanian. Pusat Pengembangan Penyuluhan Pertanian. Badan Pengembangan SDM Pertanian Deptan. http://www.Deptan.go.id/ bpsdm/pedum/PedomanRPP2008.pdf.

Ramirez, R. and Wendy, Q. 2004. Communication for Development. International Development Research Centre and the Food and Agriculture Organization of The United Nations. 2004.

Rangkuti, F. 2006. Analisis SWOT Teknik Membedah Kasus Bisnis. PT Gramedia Pustaka Utama. Jakarta.

Sonbait. L. Y. 2011. Identifikasi Problem Komunikasi Peternak di Kabupaten Manokwari Papua Barat. Jurnal Ilmu Komunikasi 9 (2), Mei - Agustus 2011: 157165.

Suparta, N. 2007. Penyuluhan Sistem Agribisnis suatu Pendekatan Holistik. Program Studi Sosial Ekonomi dan Agribisnis. Fakultas Peternakan Universitas Udayana. Denpasar.

Wulyono, T. dan Ahsin, D. 2013. Strategi Pengembangan Itik dalam Rangka Peningkatan Pendapatan Peternak di Kabupaten Kediri. Jurnal Manajemen Agribisnis 13 (2), Juli 2013 : 17 - 30. 